\title{
Vector control intervention towards interruption of transmission of Chagas disease by Rhodnius prolixus, main vector in Guatemala
}

\author{
Ken Hashimoto ${ }^{1+}$, Hugo Álvarez² , Jun Nakagawa ${ }^{3}$, Jaime Juarez ${ }^{1}$, \\ Carlota Monroy ${ }^{4}$, Celia Cordón-Rosales ${ }^{5}$, Enrique Gil ${ }^{1}$
}

\begin{abstract}
${ }^{1}$ Unit of Epidemiology, Communicable Diseases and Priority Problems, Pan American Health Organization/World Health Organization, Guatemala, Guatemala ${ }^{2}$ National Chagas Disease Control Programme, Ministry of Health, Guatemala, Guatemala ${ }^{3}$ Chagas Disease Control Project, Japan International Cooperation Agency, Guatemala, Guatemala ${ }^{4}$ Laboratory of Applied Entomology and Parasitology, University of San Carlos, Guatemala, Guatemala ${ }^{5}$ Center for Health Studies, Del Valle University, Guatemala, Guatemala
\end{abstract}

In Guatemala, the Ministry of Health (MoH) began a vector control project with Japanese cooperation in 2000 to reduce the risk of Chagas disease infection. Rhodnius prolixus is one of the principal vectors and is targeted for elimination. The control method consisted of extensive residual insecticide spraying campaigns, followed by community-based surveillance with selective respraying. Interventions in nine endemic departments identified 317 villages with $\mathrm{R}$. prolixus of 4,417 villages surveyed. Two cycles of residual insecticide spraying covered over $98 \%$ of the houses in the identified villages. Fourteen villages reinfestated were all resprayed. Between 2000-2003 and 2008 , the number of infested villages decreased from 317 to two and the house infestation rate reduced from $0.86 \%$ to $0.0036 \%$. Seroprevalence rates in 2004-2005, when compared with an earlier study in 1998, showed a significant decline from $5.3 \%$ to $1.3 \%$ among schoolchildren in endemic areas. The total operational cost was US\$ 921,815, where the cost ratio between preparatory, attack and surveillance phases was approximately 2:12:1. In 2008, Guatemala was certified for interruption of Chagas disease transmission by R. prolixus. What facilitated the process was existing knowledge in vector control and notable commitment by the $\mathrm{MoH}$, as well as political, managerial and technical support by external stakeholders.

Key words: Rhodnius prolixus - Chagas disease - trypanosomiasis - Guatemala - vector control - neglected tropical diseases

A century has passed since Carlos Chagas first described the disease caused by the protozoan, Trypanosoma cruzi, in 1909. Control of Chagas disease has made notable achievements in the last two decades (Schofield et al. 2006). Throughout the American continent, the number of infected people appears to have been halved from 16-18 million in the early 1990s to eight-nine million today (WHO 1991, PAHO 2006).

The principal intervention method against Chagas disease involves elimination of the domestic vectors, responsible for well over $80 \%$ of disease transmission (Schofield 1994). In South America, the elimination campaign against the main vector, Triatoma infestans, contributed significantly to alleviation of the endemic problem, with vector-borne transmission interrupted in Uruguay in 1997, Chile in 1999 and Brazil in 2006 (Moncayo 1999, Massad 2008).

Financial support: MoH Guatemala, JICA, PAHO, USAC, UVG, MSF Spain, ECLAT

KH current address: Chagas Disease Control Central America, JICA, Tegucigalpa, Honduras

JN current address: Malaria, other Vector-borne and Parasitic Diseases, WHO/Western Pacific Region, Manila, Philippines EG current address: Chronic Disease Prevention and Control, PAHO/WHO Mexico, Mexico

+Corresponding author: hashimok@gmail.com

Received 16 February 2012

Accepted 19 July 2012
In Central America, 1.8 million people were estimated to be infected by Chagas disease in 2000 (WHO 2000). The principal vectors in this region are Rhodnius prolixus and Triatoma dimidiata (Ponce 1999). R. prolixus is considered a candidate for complete elimination from the region, because of its strictly domestic habitat in Central America, particularly in thatched roofs, and its high susceptibility to pyrethroid insecticides (Tabaru et al. 1998). T. dimidiata is targeted for elimination only in the domestic areas because of its silvatic habitats in some areas (PAHO 2002, 2003a).

The estimated number of Guatemalans infected with Chagas disease in 2000 was 730,000 or $6.5 \%$ of the entire population (WHO 2000). In the eastern region of Guatemala, where both of the principal vector species were prevalent, with an overall house infestation rate of $20.2 \%$, serological prevalence among schoolchildren was $5.3 \%$ (Rizzo 2003). In blood banks in Guatemala, sero-reactive rates of T. cruzi varied between $0.6-1.4 \%$ during 1999 and 2007(PAHO 2003b, 2004, 2007).

$R$. prolixus is a more efficient vector than T. dimidiata. In a Guatemalan village, where approximately $8 \%$ of houses were predominantly infested by $R$. prolixus, $38.3 \%$ of the population were serologically positive for $T$. cruzi (Paz-Baily et al. 2002). In comparison, another village with about $25 \%$ of house infestation only by $T$. dimidiata was associated with an $8.9 \%$ infection rate among the population (Paz-Baily et al. 2002). Similar tendencies were also reported in Honduras (Ponce et al. 1993).

Historical distribution of R. prolixus in Guatemala $R$. prolixus is believed to have been introduced to El Sal- 
vador from Venezuela via a laboratory in France between 1912-1914 for entomological laboratory studies (Zeledón 2004). In 1915, it appears that the laboratory-bred $R$. prolixus escaped by accident. Preceding the discovery of the first human infection in Guatemala in 1932 (Reichenaw 1933), the presence of the vector became evident in Guatemala by 1934 (De León 1943) and in Mexico by 1938 (Velasco-Castrejón \& Rivas-Sánchez 2008). In the 1950s, the distribution of $R$. prolixus had been more widespread than that of T. dimidiata in eastern Guatemala (MoH 1959), but by the 1990s the pattern became more contracted (Tabaru et al. 1999). The reduced distribution of $R$. prolixus is attributable to domestic insecticide spray campaigns during the 40 -year malaria eradication programme from the mid-1950s (Yamagata \& Nakagawa 2006) and to rural house improvements - particularly decreased use of thatched roofs in recently built houses. A national entomological survey in the late 1990s in the 22 departments showed that six departments were infested with $R$. prolixus and 16 departments were with $T$. dimidiata (Tabaru et al. 1999). Further studies raised the number of infested departments to nine for $R$. prolixus and 21 for T. dimidiata (Yamagata \& Nakagawa 2006).

Central American goals for Chagas disease control - Central American countries (Guatemala, Belize, El Salvador, Honduras, Nicaragua, Costa Rica and Panama) are members of a regional initiative for Chagas disease control [Iniciativa de los Países de Centro América para la Interrupción de la Transmisión Vectorial, Transfusional y Atención Médica de la Enfermedad de Chagas (IPCA)] with a common goal to interrupt the transmission of Chagas disease. This is to be achieved through three specific objectives: elimination of $R$. prolixus, reduction of $T$. dimidiata and screening of blood for transfusion.

The idea of the Central American initiative arose during a technical meeting organised by the European Commission Latin America Triatomine Research Network (ECLAT) in Santo Domingo de los Colorados in Ecuador in 1995 (Schofield et al. 1996). The IPCA concept derived from the successful joint efforts of the South American initiative for Chagas disease control (Schofield et al. 1996). In 1997, the initiative was recognised by Ministerial resolution of the 13th Meeting for the Health Sector of Central America in Belize (Yamagata \& Nakagawa 2006). Later in 1997, the Central American countries held the first meeting and formally launched the IPCA initiative in Honduras (WHO 1997). To reinforce the political impetus and begin detailed technical planning, the second ECLAT meeting took place in Tegucigalpa in 1998 (Schofield \& Ponce 1999). In the 51st World Health Assembly in 1998, IPCA and its goals became internationally acknowledged by resolution 51.14 (WHO 1998).

Chagas disease control activities towards the IPCA goals began in most of the Central American countries in 1998. The Government of Taiwan, who had been interested in financing the Chagas disease control activities since the launching of IPCA in 1997, donated US\$ 500,000 to each IPCA member country to initiate the interventions. However, Guatemala lost the opportunity, because the hurricane Mitch struck in October 1998 and all donated funds were utilised for emergency relief with authorisation of the Taiwanese government. In 2000, the Guatemalan Ministry of Health $(\mathrm{MoH})$ began a vector control project assisted by the Japan International Cooperation Agency (JICA) (Yamagata \& Nakagawa 2006). This project was designed reflecting the results of JICA's Tropical Diseases Investigation and Control project during 1991-1998 in Guatemala.

The paper describes the vector control interventions against $R$. prolixus from 2000-2008 and its impact on $T$. cruzi seroprevalence on children in endemic areas for Chagas disease in Guatemala.

\section{SUBJECTS, MATERIALS AND METHODS}

Evaluation of the impact of the vector control intervetion focused on the levels of distribution and infestation of $R$. prolixus and seroprevalence of children in areas with a history of the vector. For the distribution and infestation rates, the baseline survey was conducted from 2000-2003 and evaluation continued until 2008. Seroprevalence was analysed by comparison with a study in 1999 as the baseline and the results obtained by evaluation from 2004-2006.

Setting - Guatemala has an area of $108,889 \mathrm{~km}^{2}$, with an altitude range of $0-4,220 \mathrm{~m}$ above sea level. The country is organised into 22 departments with $331 \mathrm{mu}-$ nicipalities. Total population was 11.2 million in 2002, with 45\% living in rural areas (INE 2002).

The National Chagas Disease Control Programme implemented a vector control project with technical, financial and managerial support by JICA from March 2000-July 2005. The initial two-year period of the project targeted four departments (Chiquimula, Zacapa, Jutiapa and Santa Rosa). The second phase of the project, from 2002-2005, included six more departments (Jalapa, El Progreso, Baja Verapaz and Alta Verapaz, Huehuetenango and El Quiché).

Intervention against $R$. prolixus - The National Chagas Disease Control Programme of the Guatemalan $\mathrm{MoH}$ implemented the vector control interventions through three phases: preparatory, attack and surveillance.

Preparatory phase (2000-2003): "Entomological Baseline Survey" - Between 2000-2003, 55,569 houses of 4,417 villages in 10 departments were surveyed for the presence of the vectors, $R$. prolixus and $T$. dimidiata (Table I). The target villages and departments were selected for investigation on the basis of risk factors, such as a history of the presence of the vectors, houses made with thatch-roof and mud walls, which are usually located in economically deprived rural areas and altitudes between 800-1,600 $\mathrm{m}$ (MoH 2003). Throughout the survey, technical, operational and monitoring assistance was provided by the Medical Entomology Laboratory of the MoH, San Carlos University of Guatemala (USAC), Del Valle University of Guatemala (UVG) and JICA. These institutions, except JICA, began quality control entomological surveys in the departments in 2003, to evaluate and improve the survey techniques of departmental operational teams. 
During the baseline survey, a pair of trained entomological technicians of the vector-borne disease control programme [Enfermedades Transmitidas por Vectores (ETV)] of each department investigated houses with the risk factors. Each pair surveyed 20 houses per village or all houses in villages with fewer than 20 houses. The house number was standardised to optimise the limited resources of ETV and to increase coverage of the survey and was nationally implemented in 2003 (MoH 2003). The technicians searched domestic and peridomestic areas of each house with a torch and forceps for up to 30 min per house or until the first live triatomine was found. The domestic area included the roof, walls, floor, beds and firewood, located under the roof. The peridomestic zone refers to chicken coops and corrals for domestic animals located approximately $2-30 \mathrm{~m}$ from the house (Hashimoto et al. 2006). During the house visits, the entomological technicians informed the householders about Chagas disease and the physical appearance of the vectors. Also, primary schools were visited occasionally for educational talks on disease prevention.

Attack phase (2000-2005): "Residual Insecticide Spraying" - After completion of the baseline survey, two cycles of residual spraying were applied in the villages infested with $R$. prolixus. The interval between the two cycles was four-18 months (Yamagata \& Nakagawa 2006). The time variation mainly depended on availability of resources. Each technician sprayed an average of eight houses per day.

For insecticides, third-generation pyrethroids were utilised because of their proven efficiency in South and Central America for Triatominae control. The following four types were used, according to the availability in the local market: beta-cyfluthrin [12.5\% suspension concentrate (s.c.) at $25 \mathrm{mg}$ active ingredient (a.i.) $\left./ \mathrm{m}^{2}\right]$, cyfluthrin [10\% wettable powder (w.p.) at $50 \mathrm{mg}$ a.i. $\left./ \mathrm{m}^{2}\right]$, deltamethrin $\left(10 \%\right.$ s.c. or $5 \%$ w.p. at $25 \mathrm{mg}$ a.i. $\left./ \mathrm{m}^{2}\right)$ and lambdacyhalothrin (10\% w.p. at $30 \mathrm{mg}$ a.i. $/ \mathrm{m}^{2}$ ) (Yamagata \& Nakagawa 2006).

The impact of each spraying was evaluated threesix months after each intervention by the entomological technicians of the department. The survey aimed to evaluate 20 houses per village or all houses in villages with fewer than 20 houses. The houses were evaluated applying the same investigation methods and techniques as in the baseline survey. The infestation index was calculated as the (number of houses infested with vector/ number of houses surveyed) $\mathrm{x} 100$.

Surveillance phase (2003-2008): "Entomological Vigilance and Selective Spraying" - To maintain the effects of the insecticide spraying, community-based and institutional surveillance systems were implemented in the villages infested with $R$. prolixus. The communitybased surveillance consists of three functional components: (i) reporting the presence of the vector by householders via Chagas volunteers or school teachers in each village, (ii) entomological investigation of the reported houses and plan for selective spraying by the institutional technicians and (iii) insecticide spraying of all houses in the infested villages by the technicians within one month after the confirmed report.

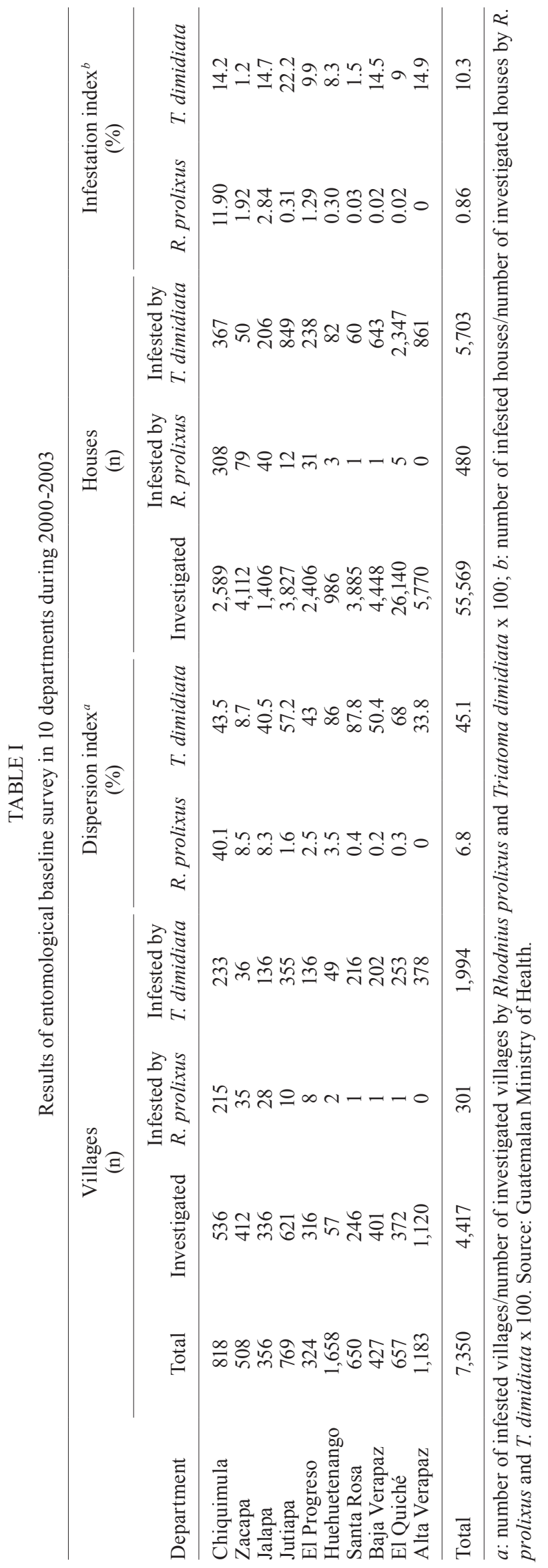


For the institutional surveillance, the entomological technicians visited 20 houses, or all if less than 20 houses existed in the village, with the risk factors including the history of $R$. prolixus, at least every two-three years. A pair of entomological technicians investigated the houses with the same method and techniques as the baseline survey and evaluation. When $R$. prolixus was found in the survey, all houses of the village were sprayed within a one-month period.

The departments implemented the phases of vector control in accordance with the workload and institutional resources and capacity, as well as JICA's project periods. In highly infested areas, insecticide spraying or attack phase followed immediately after the baseline survey. This resulted in an overlap of intervention phases in each department. The duration of the preparatory, attack and surveillance phases were: 2000, 2000-2002, 2003+ in Zacapa, 2000-2002, 2001-2004, 2003+ in Jutiapa, 20002003, 2001-2005, 2006+ in Chiquimula, 2000-2001, 2000-2002, 2003+ in Japala, 2000-2001, 2000-2003, 2004+ in Santa Rosa, 2002-2004, 2003-2004, 2005+ in El Progreso, 2001-2002, 2003-2004, 2005+ in Baja Verapaz, 2002-2003, 2003-2004, 2005+ in Alta Verapaz, 2002-2003, 2003-2005, 2005+ in Huehuetenango and 2002, 2003-2005, 2005+ in El Quiché.

Serological evaluation of the vector transmission In the 317 villages with a history of $R$. prolixus infestation, two serological surveys were conducted. The first round during 2004-2005 was aimed at all children over six months and under six years of age and attempted to determine the disease transmission level or incidence rates after the intervention. The interval between the first insecticide spraying and the serological evaluation was two-four years. The second evaluation in 2005-2006 targeted all schoolchildren between six-14 years of age in the same 317 villages.

Utilising filter paper, fingerprick blood samples were collected in the villages by personnel of the local health centres, including physicians, nurses and entomological technicians. The collected samples were dried, registered and sent to the National Laboratory of Health of the $\mathrm{MoH}$ in Guatemala city. All samples were eluted and examined. For the evaluation of 2004-2005, the samples were tested by the National Laboratory primarily using Wiener Lab raw antigen ELISA kits and confirmed by USAC with Pathozyme recombinant ELISA kits and Fujirebio GPAT (Gelatin Particle Agglutination Test). For the 2005-2006 survey, all samples were examined once with recombinant ELISA kits of Wiener Lab by the National Laboratory.

In both surveys, agreements were made verbally with the parents or school teachers of the children prior to the blood sampling for ethical use of the collected samples. All confirmed cases were treated with either benznidazole or nifurtimox depending on the availability at $\mathrm{MoH}$. In neither survey, mothers of the seropositive were tested for possibilities of congenital transmission.

Statistical method - For analysis of infestation levels of $R$. prolixus, $2 \times 2$ contingency tables were employed to compare the proportion of infested houses and non-infest- ed houses, before and after the interventions. More specifically, the entomological baseline was compared with the results of evaluation of two cycles of insecticide spraying and the most recent infestation data in the surveillance phase. Because no systematic, large-scaled entomological investigation was carried out during the surveillance phase, the investigated houses in the baseline were regarded as generalised risky houses in the analysis.

Comparison of the seroprevalence in schoolchildren between 1999 and 2005-2006 also used a chi-square test. The survey in 1999 had found 235 infected out of 4,450 children randomly sampled ( $95 \%$ confidence level, $90 \%$ power and $5 \%$ precision) in the eastern five departments (Rizzo et al. 2003). Since the two surveys targeted different geographical areas, the direct comparison provided temporal and spatial differences. Also, because of application of distinct sampling and testing methods, these sources of variation contributed to observed differences. Accordingly, in addition to the vector control intervention, several potential sources of variations may have been involved in analysis.

\section{RESULTS}

Impact on vector infestation levels - A total of 317 villages were sprayed during 2000-2004, of which $72.6 \%$ were located in the department of Chiquimula. In addition to the 301 villages identified with $R$. prolixus in the baseline survey, a further 16 villages were reported infested by the villagers. All infestation and reinfestation were found in domestic environments in line with previous studies (Tabaru et al. 1998). All villages found infested in the baseline study were sprayed in two consecutive cycles and a fraction (40/317) was sprayed in a third or more cycles. More than three cycles of spraying were applied to repeatedly infested houses due to a thick thatched-roof. The insecticide spraying covered 37,470 houses for the first cycle and 40,991 for the second (Table II). This increase in the number between the cycles is attributable to construction of new houses. Two cycles of residual spraying achieved over $98 \%$ of coverage. The remaining houses were not covered because of absence or refusal of the householders.

As a result of the insecticide spraying campaigns, the house infestation rates of $R$. prolixus decreased from $0.9 \%$ at the baseline to $0.4 \%$ after the first spraying [odds ratio $(\mathrm{OR})=0.4358,95 \%$ confidence interval $(\mathrm{CI})=0.2684-0.7076, \chi^{2}$ test statistic $\left.=11.9, \mathrm{p}<0.001\right]$ and to $0.1 \%$ after the second spraying $(\mathrm{OR}=0.1394,95 \%$ $\mathrm{CI}=0.0661-0.2941, \chi^{2}$ test statistic $\left.=36.6, \mathrm{p}<0.0001\right)$ (Table III). In Chiquimula, because the number of investigated houses after the first insecticide spraying was smaller than expected due to misunderstanding of methodology, ETV repeated the entomological evaluation in 2,485 houses of 122 villages. This investigation found 30 houses infested with $R$. prolixus and another 30 houses with $T$. dimidiata.

Comparing the infestation levels between the baseline in 2000-2003 and the results in 2008, the number of infested villages with $R$. prolixus decreased from 317 to two $\left(\mathrm{OR}=0.003,95 \% \mathrm{CI}=0.0004-0.023, \chi^{2}\right.$ test statistic $=322.7, \mathrm{p}<0.0001)($ Fig. 1). During the same period, the 
infestation rate in the endemic areas reduced significantly from $0.86-0.0036 \%(\mathrm{OR}=0.0041,95 \% \mathrm{CI}=0.001$ $0.0164, \chi^{2}$ test statistic $\left.=476.1, \mathrm{p}<0.0001\right)$.

According to the results of the entomological surveys, significant reduction was observed in the house infestation rates of $R$. prolixus after the first cycle $(\mathrm{OR}=0.440$, $95 \% \mathrm{CI}=0.271-0.715)$ and the second cycle $(\mathrm{OR}=0.316$, $95 \% \mathrm{CI}=0.131-0.763)$. The combined effects of the two cycles were larger $(\mathrm{OR}=0.138,95 \% \mathrm{CI}=0.065-0.291)$.

It should be noted that, although the same houses were searched in successive assessments, they were treated as independent in the analyses because individual households were not distinguished in the datasets. Hence, the effect size estimate we report has to be interpreted with caution, particularly as regards its precision. However, the very large effect of the intervention gives us confidence that the risk of type I error is reasonably small.

During the surveillance phase of 2003-2008, reinfestion of the 14 villages was reported within two-five years after the second insecticide spraying. Six villages were found infested by the entomological evaluation of ETV in Chiquimula during 2006. The rest were reported by the villagers through the community-based surveillance system. ETV continued visiting the villages with history of $R$. prolixus throughout the surveillance phase (Supplementary data).

For quality control of entomological surveys in the departments, the intervened villages with history of $R$. prolixus were visited by monitoring teams of the Medical Entomology Laboratory of the $\mathrm{MoH}$ and local universities (USAC and UVG). Each team evaluated distinct departments. The target villages were selected blindly to the departmental ETV personnel and were visited and evaluated jointly with the local entomological technicians, searching for the possible presence of the vector, registry of the house visit and opinions by the householders. Among the 113 villages evaluated with this method through 2003 and 2007, four villages were found infested with $R$. prolixus (Table IV).

Impact on seroprevalence - Out of 7,914 samples for the serological evaluation of children under six years of age, 29 were confirmed positive with two of the three different tests (raw antigen ELISA, recombinant ELISA and GPAT) and 14 were reactive at least in one of the tests. In total, 43 children were regarded as positive.

Seroprevalence of schoolchildren in the endemic areas reduced from 5.3\% (Rizzo et al. 2003) in 1999 to $1.3 \%$ in $2005-2006(\mathrm{OR}=0.2306,95 \% \mathrm{CI}=0.1921-$ $0.2767, \chi^{2}$ test statistic $\left.=292.81, \mathrm{p}<0.0001\right)($ Table V). This effect of the intervention might have been even more evident, because whereas the study in 1999 took all villages in consideration in the random sampling, the evaluation in 2005-2006 targeted only villages with history of $R$. prolixus.

The reduction in seroprevalence between 1999 and 2005-2006 was larger among six-10 years-old children $(123 / 2,516$ vs. $87 / 11,207 ;$ OR $=0.15,95 \%$ CI $0.12-0.20)$ than among 11-16-year-olds (112/1,931 vs. 137/7,275; OR $=0.31,95 \%$ CI 0.24-0.40) (Table IV). This two-fold difference is probably due, at least in part, to the reduction of exposure among the youngest cohort brought about by vector control interventions.

Age-stratified data demonstrate a gradual increase in seroprevalence along the age of children (Fig. 2). A notable reduction is observed in children aged between two-four years-old, suggesting possible effects of the intervention. In the survey with children under six yearsold, the seropositive individuals showed a mean age of 3.6 years. A mean spell between the birth and the insecticide spraying was 2.7 years. Differences between the sample numbers are observed between Fig. 2 and Table $\mathrm{V}$, due to untraceable missing age-data in both surveys; 760 children under six years-old and 180 children over

TABLE II

Results of residual insecticide house spraying in nine departments with presence of Rhodnius prolixus during 2000-2004

\begin{tabular}{|c|c|c|c|c|c|c|c|c|c|}
\hline \multirow[b]{3}{*}{ Department } & \multicolumn{3}{|c|}{ First cycle } & \multicolumn{3}{|c|}{ Second cycle } & \multicolumn{3}{|c|}{ Third or more cycles } \\
\hline & \multicolumn{2}{|c|}{$\begin{array}{l}\text { Houses } \\
\text { (n) }\end{array}$} & \multirow{2}{*}{$\begin{array}{c}\text { Coverage } \\
(\%)\end{array}$} & \multicolumn{2}{|c|}{$\begin{array}{l}\text { Houses } \\
\text { (n) }\end{array}$} & \multirow{2}{*}{$\begin{array}{c}\text { Coverage } \\
(\%)\end{array}$} & \multicolumn{2}{|c|}{$\begin{array}{l}\text { Houses } \\
\text { (n) }\end{array}$} & \multirow{2}{*}{$\begin{array}{c}\text { Coverage } \\
(\%)\end{array}$} \\
\hline & Programmed & Sprayed & & Programmed & Sprayed & & Programmed & Sprayed & \\
\hline Chiquimula & 27,072 & 26,759 & 98.8 & 30,964 & 30,461 & 98.4 & 3,479 & 3,441 & 98.9 \\
\hline Zacapa & 3,985 & 3,985 & 100 & 4,193 & 4,193 & 100 & 235 & 235 & 100 \\
\hline Jalapa & 4,257 & 4,112 & 96.6 & 4,382 & 4,251 & 97 & 618 & 600 & 97.1 \\
\hline Jutiapa & 1,074 & 1,072 & 99.8 & 1,072 & 1,072 & 100 & 773 & 773 & 100 \\
\hline El Progreso & 1,182 & 1,182 & 100 & 1,258 & 1,221 & 97.1 & 0 & 0 & - \\
\hline Huehuetenango & 222 & 195 & 87.8 & 225 & 208 & 92.4 & 249 & 194 & 77.9 \\
\hline Santa Rosa & 96 & 96 & 100 & 111 & 105 & 94.6 & 112 & 103 & 92 \\
\hline Baja Verapaz & 56 & 56 & 100 & 52 & 52 & 100 & 0 & 0 & - \\
\hline El Quiché & 16 & 16 & 100 & 9 & 9 & 100 & 0 & 0 & - \\
\hline Total & 37,960 & 37,473 & 98.7 & 42,266 & 41,572 & 98.4 & 5,466 & 5,346 & 97.8 \\
\hline
\end{tabular}

source: Guatemalan Ministry of Health. 


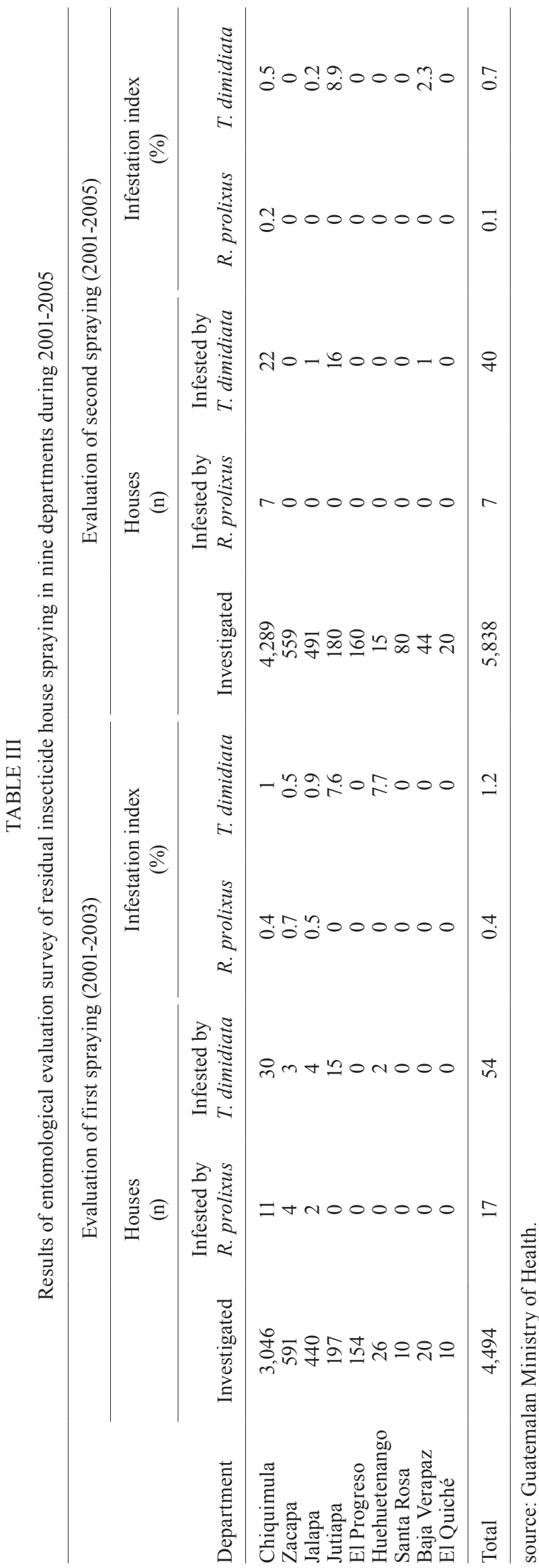

six years-old. Another limitation is that although the evaluations aimed to include all children of the target age group, the coverage could not be confirmed, because of unavailability of updated census data.

Cost of intervention - The operational cost of the intervention was calculated in terms of the insecticide spraying and the entomological evaluation of the sprayed houses. In an earlier study on intervention against $R$. prolixus in Zacapa, one of the target departments in Guatemala (Nakagawa et al. 2003), the cost of insecticide spraying - consisting of the insecticide, labour and transport - was US\$ 9.12 per house. Considering that each of the field staff could either spray an average of eight houses per day, or evaluate 10 houses per day, the labour and transport costs for surveillance can be estimated as $80 \%$ of the spray cost. Accordingly, the entomological evaluation is estimated to cost US\$2.04 per house (Supplementary data).

Based on the unit cost calculation of US\$ 2.04 for entomological survey and US\$ 9.12 for spraying, a total of US\$ 921,815 was spent as the direct cost of intervention against $R$. prolixus during 2000-2008 (Table VI). The cost ratio between preparatory, attack and surveillance phases was approximately 2:12:1, respectively.

Estimated overall investment of vector control against $R$. prolixus by MoH was US $\$ 5.54$ million from $2000-2008$, in which $40 \%$ of the amount was spent between 2006-2008. The direct cost of US\$ 5.08 million was composed of $96 \%$ of human resources, including salaries and travel expenses of managers and directors of the central and departmental offices, $2 \%$ of diagnostic kits and medicine and $2 \%$ of insecticides, spraying equipment and maintenance kits. Out of the US\$ 0.46 million indirect costs, $50 \%$ was spent on vehicle main-
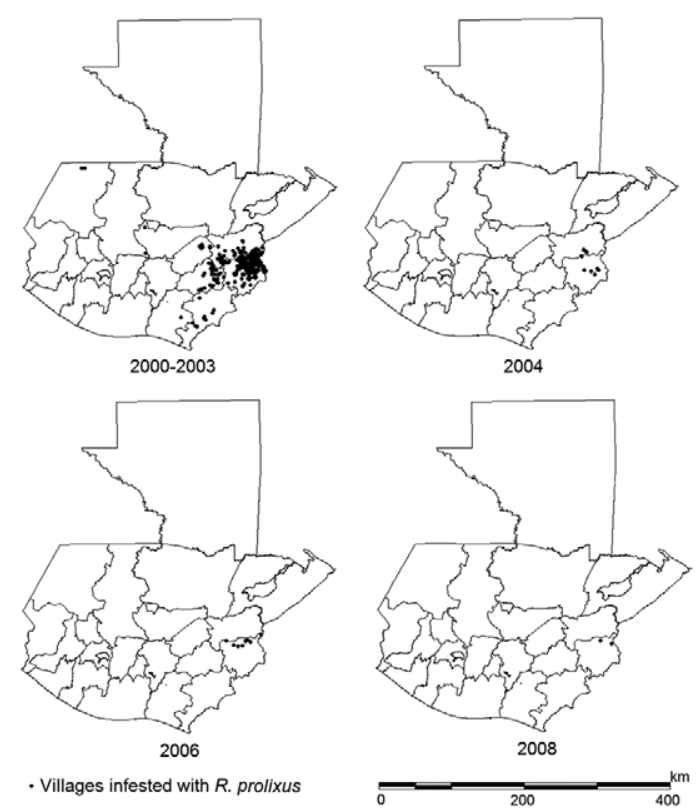

Fig. 1: distribution of villages infested with Rhodnius prolixus from 2000-2008 in Guatemala. 
tenance, insurance and fuel expenses, $40 \%$ was use of office buildings and infrastructure and $10 \%$ was office utilities and secretary service.

Investment against $R$. prolixus by JICA totalled approximately US $\$ 2.32$ million between 2000-2008, where $3.5 \%$ was expended from 2006-2008 as a follow-up of the project. The direct cost of US $\$ 2.25$ million consisted of $61 \%$ of human resources, including salaries and travel expenses of the Japanese managers, volunteers, locally contracted consultants and drivers, $23 \%$ of purchase of insecticides, spraying equipment and maintenance kits, $12 \%$ of acquisition of new vehicles, $2 \%$ of meetings and training and $1 \%$ of field utilities such as forceps, torches, GPSs, protection for sprayers and educational materials. US\$ 0.07 million of the indirect cost was summed up by $46 \%$ of office equipment including computers, software, printers and projectors, $31 \%$ of vehicle maintenance, insurance and fuel expenses and $22 \%$ of office utilities, including paper, phones and photocopiers.

Pan American Health Organization (PAHO) also financed $\mathrm{MoH}$ for soft components of the direct cost such as training, seminars, meetings and educational materials and official documents by providing US $\$ 73,700$ during 2002-2005. The project was designed to reinforce the institutional capacities of $\mathrm{MoH}$ in coordination with El Salvador and Honduras, who shared the same IPCA goals as part of PAHO's scheme of the Technical Cooperation among Countries.

\section{DISCUSSION}

The vector control intervention from 2000-2008 significantly reduced the risk of infection with Chagas disease by $R$. prolixus in endemic areas of Guatemala. In 2008, only two sporadic foci were found with presence of the vector. Effects of the intervention were also demonstrated in reduction of house infestation levels by $T$. dimidiata, showing dramatic early decline by the first cycle of insecticide spraying. Health promotion during the house visits also resulted in house improvement in some households, although the number was not registered. This may have contributed in reduction of the risks of vector infestation. Taken together, the seroprevalence of children in endemic areas considerably declined and a total estimated population of 392,000 has been protected from the infection risk.

Based on the results of the vector control intervention and evaluation, IPCA certified in 2008 that Chagas disease transmission by $R$. prolixus was interrupted in Guatemala. The Guatemalan experience suggests that the interruption of disease transmission can be achieved by the traditional vector control method of insecticide spraying followed by sustained surveillance. What facilitated the process was the MoH's commitment, as well as political, managerial and technical support by external stakeholders, especially support to the decentralised health systems.

Key success factors - One key factor for the success was availability of effective and simple vector control methods, consisting of massive insecticide spraying and followed by surveillance and selective respraying (Dias $\&$ Schofield 1999). Because of the susceptibility of $R$. prolixus to pyrethroid insecticide (Tabaru et al. 1998, Dias \& Schofield 1999), merely $5 \%$ of the villages reported continuing infestation of $R$. prolixus. Also, application of insecticide spraying was both technically and methodologically feasible. Most ETV coordinators had experience with the malaria eradication campaign. Contracted entomological technicians could spray houses after two-day training under supervision of the brigade chief. Implementation of the surveillance system followed the concepts and experience accumulated during the malaria control programme, where locally trained volunteers collected and reported samples from each community to the ETV programme.

Another noteworthy factor was the continuous commitment by different sections of the $\mathrm{MoH}$, scientific communities and donors towards the common goal. In

TABLE IV

Results of quality control surveillance by the Medical Entomological Section and the universities

\begin{tabular}{|c|c|c|c|c|c|c|c|}
\hline \multirow[b]{2}{*}{ Department } & \multicolumn{2}{|c|}{$\begin{array}{l}\text { Villages } \\
\text { (n) }\end{array}$} & \multirow{2}{*}{$\begin{array}{c}\text { Dispersion } \\
\text { index } \\
(\%)\end{array}$} & \multicolumn{2}{|c|}{$\begin{array}{l}\text { Houses } \\
\text { (n) }\end{array}$} & \multirow{2}{*}{$\begin{array}{l}\text { Infestation } \\
\text { index } \\
(\%)\end{array}$} & \multirow[b]{2}{*}{$\begin{array}{l}\text { Surveyed } \\
\text { years }\end{array}$} \\
\hline & Surveyed & $\begin{array}{l}\text { Infested by } \\
R . \text { prolixus }\end{array}$ & & Surveyed & $\begin{array}{l}\text { Infested by } \\
R \text {. prolixus }\end{array}$ & & \\
\hline Chiquimula & 59 & 4 & 6.8 & 1,302 & 6 & 0.5 & $03,04,05,06,07,08$ \\
\hline Zacapa & 15 & 0 & 0 & 262 & 0 & 0 & $04,05,06$ \\
\hline Jalapa & 16 & 0 & 0 & 298 & 0 & 0 & $03,05,06,08$ \\
\hline Jutiapa & 10 & 0 & 0 & 847 & 0 & 0 & 03,05 \\
\hline El Progreso & 8 & 0 & 0 & 520 & 0 & 0 & $03,05,06$ \\
\hline Huehuetenango & 2 & 0 & 0 & 40 & 0 & 0 & 05 \\
\hline Santa Rosa & 1 & 0 & 0 & 40 & 0 & 0 & 03,05 \\
\hline Baja Verapaz & 1 & 0 & 0 & 20 & 0 & 0 & 05 \\
\hline El Quiché & 1 & 0 & 0 & 32 & 0 & 0 & $03,05,06$ \\
\hline Total & 113 & 4 & 3.5 & 3,361 & 6 & 0.2 & - \\
\hline
\end{tabular}

source: Guatemalan Ministry of Health. 
TABLE V

Seroprevalence in children under six years-old in 2004-2005 and in schoolchildren over six years in 1999 and 2005-2006

\begin{tabular}{|c|c|c|c|c|c|c|c|c|c|}
\hline \multirow[b]{3}{*}{ Department } & \multicolumn{3}{|c|}{$\begin{array}{l}\text { Schoolchildren over } \\
\text { six years-old in } 1999\end{array}$} & \multicolumn{3}{|c|}{$\begin{array}{c}\text { Schoolchildren over } \\
\text { six years-old in 2005-2006 }\end{array}$} & \multicolumn{3}{|c|}{$\begin{array}{c}\text { Children under } \\
\text { six years-old in 2004-2005 }\end{array}$} \\
\hline & \multicolumn{2}{|c|}{$\begin{array}{l}\text { Children } \\
\text { (n) }\end{array}$} & \multirow{2}{*}{$\begin{array}{l}\text { Prevalence } \\
\quad(\%)\end{array}$} & \multicolumn{2}{|c|}{$\begin{array}{l}\text { Children } \\
\text { (n) }\end{array}$} & \multirow{2}{*}{$\begin{array}{l}\text { Prevalence } \\
\quad(\%)\end{array}$} & \multicolumn{2}{|c|}{$\begin{array}{l}\text { Children } \\
\text { (n) }\end{array}$} & \multirow{2}{*}{$\begin{array}{l}\text { Prevalence } \\
\quad(\%)\end{array}$} \\
\hline & Examined & Positive & & Examined & Positive & & Examined & Positive & \\
\hline Chiquimula & 848 & 57 & 6.7 & 10,723 & 194 & 1.8 & 5,173 & 23 & 0.4 \\
\hline Zacapa & 407 & 11 & 2.7 & 1,992 & 5 & 0.3 & 938 & 6 & 0.6 \\
\hline Jalapa & 757 & 60 & 7.9 & 1,977 & 8 & 0.4 & 813 & 1 & 0.1 \\
\hline Jutiapa & 1,441 & 60 & 4.2 & 2,138 & 7 & 0.3 & 486 & 6 & 1.2 \\
\hline El Progreso & - & - & - & 1,633 & 29 & 1.8 & 353 & 5 & 1.4 \\
\hline Huehuetenango & - & - & - & 101 & 0 & 0 & 84 & 0 & 0 \\
\hline Santa Rosa & 997 & 47 & 4.7 & 363 & 0 & 0 & 31 & 1 & 3.2 \\
\hline Baja Verapaz & - & - & - & 220 & 0 & 0 & 29 & 1 & 3.4 \\
\hline El Quiché & - & - & - & - & - & - & 7 & 0 & 0 \\
\hline Total & 4,450 & 235 & 5.3 & 19,147 & 243 & 1.3 & 7,914 & 43 & 0.5 \\
\hline
\end{tabular}

source: Guatemalan Ministry of Health, Rizzo et al. (2003).

TABLE VI

Direct cost of intervention for preparatory, attack and surveillance phases

\begin{tabular}{|c|c|c|c|c|c|c|}
\hline \multirow[b]{2}{*}{ Phase } & \multicolumn{2}{|c|}{$\begin{array}{l}\text { Houses } \\
\text { (n) }\end{array}$} & \multicolumn{3}{|c|}{$\begin{array}{l}\text { Direct costs } \\
\quad(\mathrm{US} \$)\end{array}$} & \multirow[b]{2}{*}{ Cost ratio } \\
\hline & Sprayed & Surveyed & Sprayed & Surveyed & Total & \\
\hline Preparatory & - & 55,569 & 0 & 113,361 & 113,361 & 1.7 \\
\hline Attack & 79,045 & 10,332 & 720,890 & 21,077 & 741,968 & 11.2 \\
\hline Surveillance & 5,838 & 6,492 & 53,243 & 13,244 & 66,486 & 1.0 \\
\hline Total & 84,883 & 16,824 & 774,133 & 147,682 & 921,815 & - \\
\hline
\end{tabular}

$a$ : proportion of total direct costs between the preparatory, attack and surveillance phase, calculated with the cost of surveillance phase as the denominator. Source: Guatemalan Ministry of Health, Nakagawa et al. (2003).

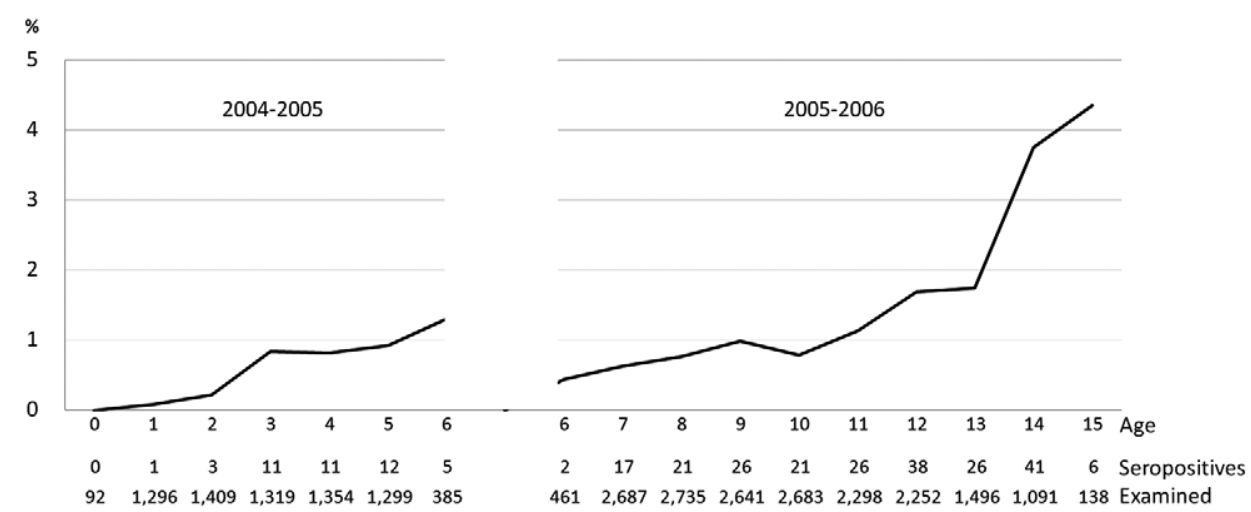

Fig. 2: age stratified seroprevalence of children in 2004-2005 and 2005-2006 in Guatemala. 
addition to assuring temporary operational personnel for seven years, the MoH directed the operation by means of manuals, training and technical advisory for vector control, clinical diagnosis and treatment. Implementation of the intervention in the decentralised health system was managed by the reinforced communication between central and operational levels, along with objective field observation by local universities and donor field staff. Although the stakeholders had their own specific objectives for the project, their intentions were always directed towards the common goal set by IPCA.

Limitations - As a vector control operation of a national programme, implemented methodologies had to be pragmatic and accordingly may have influenced the results. The entomological surveys at the preparatory, attack and surveillance phases targeted 20 houses of the highest infestation risk in each village. This vector seeking method was preferred to a random sampling, since elimination of $R$. prolixus was the principal objective, but all houses in the risk villages could not be investigated due to limited recourses. This approach, however, is likely to have biased representativeness of the infestation rates for both $R$. prolixus and $T$. dimidiata.

The direct comparison of results from the two serological surveys has limitations. In particular, since surveys targeted different geographical areas and used different sampling strategies and testing methods, the differences we report do not measure temporal variation alone: spatial, sampling and test heterogeneity were also implicitly analysed. However, we deem it unlikely that the large reduction in prevalence we report $(\sim 400 \%)$ is driven by confounding; even admitting that the effect of the intervention might be upwardly biased, we therefore conclude that children were significantly protected by vector control.

Throughout the surveys and interventions, use of the diagnostic test kits or insecticides was not standardised. Unstable procurement was a result of irregularity in availability of the stocks in the local market. All these factors may have caused further bias in the analysis and interpretation of the data.

Aid in policy, management and technology - The process of the intervention was facilitated in terms of policy, management and technology. This strategic concept derives from JICA's project design to aid activities in decentralised health systems (Yamagata et al. 2003). These three components were further developed through the interactions and dynamics between the key stakeholders.

Policy - Overall coordination for the Central American initiative was provided by the PAHO. One of the most important events for Guatemala was the IPCA annual meeting organised by PAHO since 1997, which provided an opportunity to reinforce the commitment of the IPCA member countries by sharing of the intervention results, best practices, challenges and learned lessons. Commonly identified technical issues were further discussed in specific workshops and their solutions were documented as IPCA guidelines. For instance, the criteria for certification of interruption of the disease by $R$. prolixus (PAHO 2003a), the technical guide for control of $T$. dimidiata
(PAHO 2002), the clinical diagnosis and treatment manual and laboratory procedures manual (PAHO 2003c).

In Guatemala, the political commitment grew gradually. When the Chagas disease control project began in 2000 , the IPCA policy was not yet reflected in the Guatemalan government commitment. The National Chagas Disease Control Programme existed at the central level, but with no operational directive or activity. Governmental priority developed gradually, principally through lobbying at the political level of the MoH by the Japanese project manager, the chief of the National Chagas Disease Control Programme and the chief of the Medical Entomology Laboratory. The project management team shared information on plans, achievements and impact to stimulate political ownership. This lobbying was required consistently, especially when the government changed after national elections every four years. The team also attempted to raise and maintain the priority in the departments by visiting the chiefs and executive members of the Departmental Health Offices and by inviting them to the quarterly evaluation meetings of the Chagas disease control project.

Along with the other IPCA member countries, the Guatemalan $\mathrm{MoH}$ received the PAHO evaluation mission, who reviewed the progress at the central and operational levels, provided technical advice and encouraged political commitment. The evaluation team consisted of experts in entomology, epidemiology, clinical diagnosis and management of national programmes, from other Central and South American countries. The Guatemalan programme was evaluated in 2002, 2005 and 2008, where the third mission was specific on the apparent interruption of Chagas transmission by $R$. prolixus.

Management - In the Guatemalan $\mathrm{MoH}$, the principal stakeholders were the Coordinator of the National Chagas Disease Control Programme and Chief of the Medical Entomology Laboratory at the central level and the ETV programme coordinators at the departmental level. Due to decentralisation, these actors were no longer positioned vertically in the organisational command line. They were not administratively, but technically connected to provide the top-down operational directive and the bottom-up field knowledge (Yamagata et al. 2003). In 2000, JICA dispatched a Japanese project manager to the central level and volunteer coordinators to the departmental level to be counterparts of the two key actors. The Japanese human resource allocation aimed to strengthen managerial capacity and communication of the two levels in the decentralised health system (Yamagata et al. 2003).

The Guatemalan $\mathrm{MoH}$ maintained political interest in Chagas disease and augmented the national operational capacity. The MoH employed approximately 100 entomological technicians every year during 2001-2007 for entomological survey, evaluation and insecticide spraying in the nine most endemic departments. They were selected and trained by the Departmental ETV personnel and worked as members of the operational brigades. The mobilisation of the ETV personnel was facilitated by four-wheel drive vehicles, donated to each department by JICA along with other materials such as insecticide, sprayers and diagnostic kits (Yamagata et al. 2003). 
Technology - Technical advice and problem-solving, including experience of Chagas disease control programmes in other countries, was facilitated through the ECLAT network. The intellectual transference to Guatemala was mainly observed through Central American workshops, in which ECLAT members participated and contributed in elaboration of the IPCA technical guidelines mentioned earlier (PAHO 2002, 2003a, 2003c). Support by the experienced specialists was also available through e-mail communication. This further encouraged improvement and advance of the disease control activities.

The latest technical knowledge for intervention and scientific findings were also introduced by USAC, UVG, the Médecins Sans frontières (MSF) Spain, PAHO and JICA. For example, UVG provided the baseline data for serological prevalence and entomological distribution of the endemic region. USAC shared recently discovered biological characteristics of the vectors, as well as the progress and learned lessons of their sustainable community-surveillance project, especially in house improvement techniques. Similarly, MSF Spain shared their experience of treatment of patients. PAHO distributed the technical documents of other countries and initiatives for reference. JICA introduced the use of the geographic information system for data analysis.

Invitation of short-term specialists to Guatemala resulted in another form of technical input. Using schemes of PAHO and JICA, specialists were invited for a period of one-four weeks in related areas, such as vector control, entomology, serology, clinical diagnosis, socioeconomics and monitoring and evaluation. In addition to their objective observations to the ongoing activities, the specialists provided training for the $\mathrm{MoH}$ personnel at the central and operational levels for the required skills.

Steering committee - At the central level of the $\mathrm{MoH}$, a national steering committee was formed in 2002. The regular members were comprised of the National Chagas Disease Control Programme, Medical Entomology Laboratory, National Health Laboratory and National Blood Bank Programme of the MoH and USAC, UVG, ECLAT, MSF Spain, PAHO and JICA. PAHO coordinated the committee between 2002-2003 and the National Chagas Disease Control Programme took leadership for the following years. The committee met approximately every two-three months to update the members with the latest information, feedback from the field, action plans etc. and to discuss the most important issues at that time. Such discussion by members with distinct viewpoints improved quality management, technical cooperation and harmonization of the stakeholders.

Sustainability - Existing evidence suggests that Chagas disease transmission by $R$. prolixus is interruptible in Central America and yet the challenge continues. This interruption of disease transmission implies a temporal state of removed risks and neither the elimination of the vector species nor the end of vector control against other species. To ensure persistent interruption of the disease transmission, periodic monitoring mechanisms for the vector distribution and seroprevalence are required. Although the Guatemalan $\mathrm{MoH}$ continued budgeting for the entomological monitoring after the project with JICA, there is need to assure further investment for serological surveys every few years. Political will is always essential. Intensified investment by donors may again leverage such interest and cost-effectiveness. In South America, successful interruption of Chagas transmission, however, resulted in budget-cuts. Limited surveillance operations provoked reinfestation of an efficient vector, T. infestans, in some areas (Vazquez-Prokopec et al. 2009). One possible approach is to create a world Chagas disease day as a reminder of the importance of the disease and to intensify the surveillance activities within and between countries at least once a year. When such minimum commitment is pledged, investments in the past and in the future will become more worthwhile and significant to protect public health.

\section{ACKNOWLEDGEMENTS}

To the MoH of Guatemala, USAC, UVG, PAHO, MSF, ECLAT and JICA, for continual support for the project, to $\mathrm{Mr}$ Luis Blanco, for organisation of database, and to Dr Chris Schofield and Dr Gabriel Schmunis, for revising the manuscript.

\section{REFERENCES}

De León R 1943. La trypanosomiasis Americana o enfermedad de Chagas en Guatemala. Gaceta Médica Centroamericana I: 57-60.

Dias JCP, Schofield CJ 1999. The evolution of Chagas disease (American trypanosomiasis) control after 90 years since Carlos Chagas discovery. Mem Inst Oswaldo Cruz 94 (Suppl. I): 103-121.

Hashimoto K, Cordon-Rosales C, Trampe A, Kawabata M 2006. Impact of single and multiple residual sprayings of pyrethroid insecticides against Triatoma dimidiata (Reduviiade; Triatominae), the principal vector of Chagas disease in Jutiapa, Guatemala. Am J Trop Med Hyg 75: 226-230.

INE - Instituto Nacional Estadística 2002. El Xo CENSO. Available from: ine.gob.gt/np/poblacion/index.htm.

Massad E 2008. The elimination of Chagas disease from Brazil. Epidemiol Infect 136: 1153-1164.

$\mathrm{MoH}$ - Ministry of Health 1959. Homenaje al cincuentenario del descubrimiento de la enfermedad de Chagas (trypanosomiasis Americana) 1909-1959, Sanidad Pública, Guatemala, 52 pp.

$\mathrm{MoH}$ - Ministry of Health 2003. Manual operativo de vigilancia y control y vigilancia de la enfermedad de Chagas, Programa Nacional de Vectores/Ministerio de Salud Pública y Asistencia Social, Guatemala, 10 pp.

Moncayo A 1999. Progress towards interruption of transmission of Chagas disease. Mem Inst Oswaldo Cruz 94 (Suppl. I): 401-404.

Nakagawa J, Cordón-Rosales C, Juárez J, Itzep C, Nonami T 2003. Impact of residual spraying on Rhodnius prolixus and Triatoma dimidiata in the department of Zacapa in Guatemala. Mem Inst Oswaldo Cruz 98: 277-281.

PAHO - Pan American Health Organization 2002. Taller para el establecimiento de pautas técnicas en el control de Triatoma dimidiata. La comisión intergubernamental de la Iniciativa de los Países de Centro América (IPCA) para la interrupción de la trasmisión vectorial y transfusional de la enfermedad de Chagas, $\mathrm{OPS} / \mathrm{HCP} /$ HCT/214/02, Guatemala, 36 pp.

PAHO - Pan American Health Organization 2003a. Reunión Internacional para el Establecimiento de Criterios de Certificación de la Eliminación de Rhodnius prolixus. La comisión intergubernamental de la Iniciativa de los Países de Centro América (IPCA) para la 
interrupción de la trasmisión vectorial y transfusional de la enfermedad de Chagas, OPS/DPC/CD/276/03, Guatemala, 52 pp.

PAHO - Pan American Health Organization 2003b. VI Reunión de la comisión intergubernamental de la Iniciativa de los Países de Centro América (IPCA) para la interrupción de la trasmisión vectorial y transfusional de la enfermedad de Chagas, Tegucigalpa, Honduras, 8-10 October 2003, OPS/DPC/CD/282/04, 39 pp.

PAHO - Pan American Health Organization 2003c. Normas de diagnóstico clínico, laboratorio, atención, vigilancia y control de la enfermedad de Chagas, TCC El Salvador - Honduras - Guatemala, Esquipulas, Guatemala, Mayo 2003, PAHO, 22 pp.

PAHO - Pan American Health Organization 2004. VII Reunión de la comisión intergubernamental de la Iniciativa de los Países de Centro América (IPCA) para la interrupción de la trasmisión vectorial y transfusional de la enfermedad de Chagas, Tegucigalpa, Honduras, 26-27 October 2004, OPS/DPC/CD/345/05, 23 pp.

PAHO - Pan American Health Organization 2006. Estimación cuantitativa de la enfermedad de Chagas en las Américas, OPS/HDM/ $\mathrm{CD} / 425-06,28 \mathrm{pp}$

PAHO - Pan American Health Organization 2007. X Reunión de la comisión intergubernamental de la Iniciativa de los Países de Centro América (IPCA) para la interrupción de la trasmisión vectorial y transfusional de la enfermedad de Chagas, Managua, Nicaragua, 28-30 August 2007, OPS/HDM/CD/512/08, 138 pp.

Paz-Baily G, Monroy C, Rodas A, Rosales R, Tabaru Y, Davies C, Lines J 2002. Incidence of Trypanosoma cruzi infection in two Guatemalan communities. T Roy Soc Trop Med Hyg 96: 48-52.

Ponce C 1999. Elimination of the vectorial transmission of Chagas disease in Central American countries: Honduras. Mem Inst Oswaldo Cruz 94 (Suppl. I): 417-418.

Ponce C, Ponce E, Flores M, Avila G 1993. Intervention trials of new tools to control transmission of Chagas disease in Honduras. Mem Inst Oswaldo Cruz 88 (Supp1.): 57-58.

Reichenaw E 1933. Sobre la existencia de la enfermedad de Chagas en Guatemala. Dirección de Sanidad, Guatemala, 24 pp.

Rizzo NR, Arana BA, Diaz A, Cordon-Rosales C, Klein RE, Powell MR 2003. Seroprevalence of Trypanosoma cruzi infection among school-aged children in the endemic area of Guatemala. Am J Trop Med Hyg 68: 678-682.

Schofield CJ 1994. Triatominae - biologia y control, Eurocommunica Publications, West Sussex, 80 pp.

Schofield CJ, Dujardin JP, Jurberg J 1996. Proceedings of the International Workshop on Population Genetics and Control of Tri- atominae, Santo Domingo de los Colorados, Ecuador, INDRE, Mexico City, 116 pp.

Schofield CJ, Jannin J, Salvatella R 2006. The future of Chagas disease control. Trends Parasit 22: 583-588.

Schofield CJ, Ponce C 1999. Proceedings of the Second International Workshop on Population Genetics and Control of Triatominae, Tegucigalpa, Honduras, 1999. INDRE, Mexico City, 134 pp.

Tabaru Y, Monroy C, Rodas A, Mejia M, Rosales R 1998. Chemical control of Triatoma dimidiata and Rhodnius prolixus (Reduviidae: Triatominae), the principal vectors of Chagas disease in Guatemala. Med Entomol Zool 49: 87-92.

Tabaru Y, Monroy C, Rodas A, Mejia M, Rosales R 1999. The geographic distribution of vectors of Chagas disease and population at risk of infection in Guatemala. Med Entomol Zool 50: 9-17.

Vazquez-Prokopec GM, Spillmann C, Zaidenberg M, Kitron U, Gürtler RE 2009. Cost-effectiveness of Chagas disease vector control strategies in northwestern Argentina. PLoS Negl Trop Dis 3: e300.

Velasco-Castrejón Ó, Rivas-Sánchez B 2008. Apuntes para la historia de la enfermedad. Bol Med Hosp Infant Mex 65: 57-79.

WHO - World Health Organization 1991. Control of Chagas disease. Tech Rep Ser 811: 95.

WHO - World Health Organization 1997. Reunión sobre vectores de la enfermedad de Chagas en los paises de Centroamérica, Tegucigalpa, Honduras, 22-24 October 1997, 35 pp.

WHO - World Health Organization 1998. 51st World Health Assembly, Resolution WHA 51.14, 2 pp.

WHO - World Health Organization 2000. Global Collaboration for Development of Pesticides for Public Health (GCDPP) - Challenge of Chagas Disease Vector Control in Central America. Available from: whqlibdoc.who.int/hq/2000/WHO_CDS_WHOPES GCDPP_2000.1.pdf.

Yamagata Y, Nakagawa J 2006. Control of Chagas disease. Adv Parasit 61: 129-165.

Yamagata Y, Nakagawa J, Shimoda M, Tabaru Y 2003. Management of infectious disease control in a decentralized organization - the case of the Japan-Guatemala project for Chagas disease control in Guatemala. Technol Dev 16: 47-54.

Zeledón R 2004. Some historical facts and recent issues related to the presence of Rhodnius prolixus (Stål, 1859) (Hemiptera: Reduviidae) in Central America. Entomol Vect 11: 233-246. 
Number of houses institutionally investigated during the surveillance phase

\begin{tabular}{|c|c|c|c|c|c|c|}
\hline Department & 2003 & 2004 & 2005 & 2006 & 2007 & Total \\
\hline Chiquimula & - & - & - & 1,738 & 902 & 2,640 \\
\hline Zacapa & 559 & 70 & 559 & 559 & 559 & 2,306 \\
\hline Jalapa & - & 20 & 26 & 111 & 1 & 158 \\
\hline Jutiapa & - & 200 & 200 & 200 & 60 & 660 \\
\hline El Progreso & - & - & 160 & 160 & 160 & 480 \\
\hline Huehuetenango & - & - & 20 & 20 & 20 & 60 \\
\hline Santa Rosa & - & 20 & 20 & 20 & 20 & 80 \\
\hline Baja Verapaz & - & - & 20 & 20 & 20 & 60 \\
\hline El Quiché & - & - & 16 & 16 & 16 & 48 \\
\hline Alta Verapaz & 0 & 0 & 0 & 0 & 0 & 0 \\
\hline Total & 559 & 310 & 1,021 & 2,844 & 1,758 & 6,492 \\
\hline
\end{tabular}

source: Guatemalan Ministry of Health.

Cost of insecticide spraying and entomological investigation by Enfermedades Transmitidas por Vectores programme

\begin{tabular}{|c|c|c|}
\hline & $\begin{array}{l}\text { Insecticide spraying per house } \\
\text { (US\$) }\end{array}$ & $\begin{array}{c}\text { Entomological investigation per house } \\
\text { (US\$) }\end{array}$ \\
\hline Insecticide & 6.57 & - \\
\hline Labour & 2.23 & 1.78 \\
\hline Transport & 0.32 & 0.26 \\
\hline Total & 9.12 & 2.04 \\
\hline
\end{tabular}

US\$ 1 was approximately 7.8 at time of spraying. The cost of deltamethrin is US\$ 72/kg and that of beta-cyfluthrin is US\$ 160/L. The cost of labour includes the monthly salaries and per diem (US\$245.60). The cost of transport includes fuel and the cost of the maintenance of the vehicle: 505.96 gallons of diesel oil (US\$ 1.36/gallon) was used and US\$ 996.79 was spent on the maintenance of the vehicle during the four month operation in Zacapa [adopted from Nakagawa et al. (2003)]. 